\title{
Experimental equipment for measuring physical properties of the annular hydrostatic thrust bearing
}

\author{
Michal Kozdera ${ }^{1, a}$, Sylva Drábková ${ }^{1}$ and Marian Bojko \\ ${ }^{1}$ Department of Hydromechanics and Hydraulic Equipment, Faculty of Mechanical Engineering, VŠB-Technical \\ University of Ostrava, 17. listopadu 15/2172, Ostrava, Czech Republic
}

\begin{abstract}
The hydraulic circuit, through which the mineral oil is brought, is an important part of hydrostatic bearings. The annular hydrostatic thrust bearing consists of two sliding plates divided by a layer of mineral oil. In the lower plate, there are oil grooves which distribute the liquid between the sliding areas. The hydraulic circuit is made of two basic parts: the energy source and the controlling part. The hydraulic pump, which brings the liquid into the sliding bearing, is the source of the pressure energy. The sliding bearing is weighted down by axial force, which can be changed during the process. That's why in front of the particular oil grooves control components adjusting pressure and flow size are located. This paper deals with a project of a hydraulic circuit for regulation of fluid layer in the annular hydrostatic thrust bearing and the testing equipment for measuring its physical properties. It will include the issue of measuring loading capacity and height of the fluid layer in the annular hydrostatic thrust bearing.
\end{abstract}

\section{Description of experimental equipment}

In the previous work [1] the flow in the annular multirecess hydrostatic thrust bearing was investigated by means of numerical modelling. This paper presents the design of experimental equipment which was built to verify the assumptions and results obtained from numerical experiment.

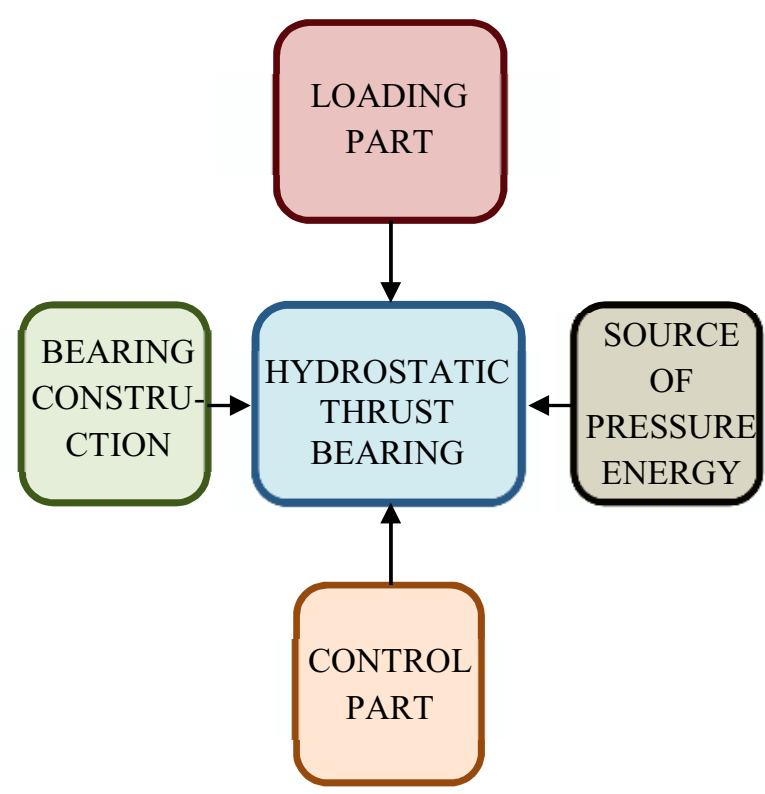

Figure 1. Basic parts of the experimental equipment for hydrostatic thrust bearing testing.
The individual parts of the experimental setup, their function and technical parameters, experimental methods and some preliminary results are presented in the paper. Experimental equipment for hydrostatic thrust bearing testing consists of several auxiliary parts, which simulate the function of the rotary table of machine tools. In practice, there is a clamping device fixed on the hydrostatic thrust bearing of the rotary table. It is used to hold the work piece. Therefore, an experimental device is designed in such a way that all the parts associated with the movement of the bearings are located below the sliding bearing. Figure 1 schematically shows basic parts of the axial hydrostatic bearing.

The control part is used to control the linear and rotational movement of the bearing sliding plate. To control the linear movement (in the vertical direction), which is due to pressure energy transmitted by mineral oil, reducers are applied. Control of rotational movement is provided by mechanical coupling which is adjustable to the required size of the bearing speed. Another important part is the construction that carries the load acting on the hydrostatic thrust bearing. The components holding the hydrostatic thrust bearing must be made very precisely to ensure the parallelism of sliding surfaces. Supporting construction should be sufficiently stiff to prevent undesirable vibrations and ensure stability against tipping. The source of pressure energy is required to feed the liquid of certain pressure and flow-rate between the sliding surfaces. As a source of pressure energy pumps are used which are the part of the hydraulic aggregate [4].

\footnotetext{
a Corresponding author: m.kozdera@gmail.com
} 
In practice, gear pumps are mostly used for the given type of application [2]. Gear pump can generate the periodic pressure pulsations caused by the flow-rate oscillation. Oscillatory flow at the outlet of the pump and thus the resulting pressure pulsations in the lines can result in variation of the fluid layer thickness in a hydrostatic thrust bearing. This may adversely affect the accuracy of position of the movable plate of the bearing.

Axial hydrostatic bearing in practice is loaded with axial force that is caused by weight of the work piece and, to a lesser extent, by the weight of the movable plate of the bearing. In the design of the experimental equipment two different types of load simulation could be applied. First, fixing the clamping device on the bearing and using the set of weights of different masses. This would enable changing the load by adding or removing the weights. As a load in order of tonnes is assumed, the exchange of weights would be very lengthy and laborious and it would not be possible to change the size of the load continuously as it is in practice. That is why the second method was used based on the load generated by linear hydraulic motor. In this case the axial load can be changed continuously. For this purpose second source of pressure energy was applied that enables the load control. Hydraulic motor was mounted above the bearing in vertical position, with its axis identical to the axis of bearing rotation.

The layout of the main parts of the experimental equipment is illustrated in figure 2. Detailed description of individual parts, which is essential for the understanding of the experimental apparatus function, will be provided in the next chapters.

\section{Description of the hydraulic circuit of the experimental equipment}

Hydrostatic thrust bearing (AHL) consists of two plates. The lower fixed plate contains lubrication recesses through which the oil is fed between the sliding surfaces. The upper rotating plate is loaded. The complete scheme of the hydraulic circuit of the experimental equipment is presented in figure 3 .

The experimental equipment has two independent hydraulic circuits - the first for the hydrostatic thrust bearing and the second for the linear hydraulic motor. The source of pressure energy of the hydrostatic thrust bearing is hydraulic aggregate. Mineral oil is stored in the steel tank (N1) with oil gauge and thermometer. Nonregulating gear pump (HG1) was selected as a source of energy this is driven by the asynchronous electric motor (EM1). For the speed regulation of the electric motor vector frequency converter (FM1) is used.

By changing the frequency on the frequency converter, the pump speed and thus the size of the flowrate change. It is therefore possible to change volumetric flow-rate of the pump to maximum extent given by the manufacturer. Between other important elements of the hydraulic aggregate belong safety valve (PV1), manometer (MPV1) and check valve (JV1), which serves to protect the pump.
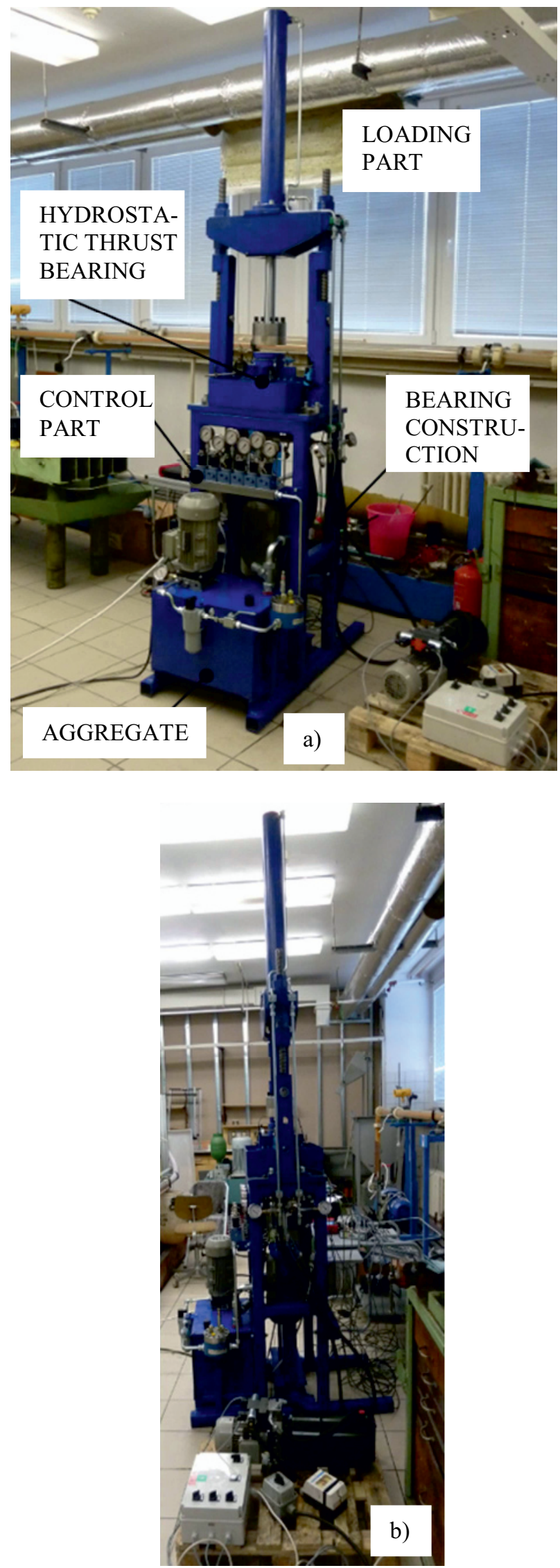

Figure 2. Experimental equipment of hydrostatic thrust bearing, a) front view, b) side view. 
Pressure filter $(\mathrm{F})$ with flow diversion valve is placed in the pressure line behind hydraulic aggregate. To close the inlet pipe of the hydrostatic thrust bearing the ball valve (V1) is used, by which we can also adjust the pressure on the safety valve (PV1). Behind the ball valve the gear flow meter $(\mathrm{P})$ is positioned in the pressure line with flow sensor (S7). After that the mineral oil is fed into the hydraulic block, where the volumetric flow-rate is divided into six lines - for each lubrication groove in the hydrostatic thrust bearing. On the hydraulic block there is a two-way flow controller (RP1 - RP6) placed in each line together with following manometer (M1 - M6). These manometers show the actual size of the pressure in each lubrication line and also enable setting the two-way flow controller. In front of the inlet to the hydrostatic thrust bearing the pressure sensor is located in each supply line (S1-S6). The magnitude of pressure measured at the inlet to the hydrostatic thrust bearing should match the size of pressure in lubrication grooves.

Load of the hydrostatic thrust bearing is generated by a double-acting linear hydraulic motor with single piston $\operatorname{rod}(\mathrm{PH})$. For control of the device the mobile hydraulic aggregate is used. It consists of a tank (N2), hydraulic pump (HG2), electric motor (EM2), check valve (JV2), safety valve (PV2) and manometer (MPV2). For control of the direction of fluid flow the three-position four-way valve $(\mathrm{R})$ is used. Setting of end position of the slide valve is controlled by solenoid valves and the midposition of the slide valve is provided with springs. Between the valve and the hydraulic motor pilot operated check valve (HZ) is located, which after switching off the pump (HG2) keeps the rod in the desired position. In the pressure and return lines the manometers M7 and M8 are located.

Furthermore, we can see in figure 3 that at the end of piston rod of hydraulic motor $(\mathrm{PH})$ the force sensor $(\mathrm{S} 8)$ is fixed. The values of variables measured by pressure sensors (S1 - S6), flow sensor (S7) and force sensor (S8) are processed and recorded at HMG 3000.

The height of the mineral oil layer between the sliding surfaces is measured by a digital indicator (U).

The upper movable plate of the hydrostatic thrust bearing is connected to an asynchronous electric motor (EM3), which governs the rotary motion of bearing. Size of the rotational speed of bearing is regulated by vector frequency converter (FM2).

\subsection{The specification of elements of the experimental equipment}

$\begin{array}{ll}\text { FM1, FM2 } & \text { frequency converter, } \\ \text { EM1, EM2, EM3 } & \text { electric motor, } \\ \text { HG1, HG2 } & \text { pump, } \\ \text { N1, N2, N3 } & \text { tank, } \\ \text { JV1,JV2 } & \text { check valve, } \\ \text { PV1,PV2 } & \text { safety valve, } \\ \text { MPV1,MPV2 } & \text { manometer, } \\ \text { F } & \text { filter, } \\ \text { V1 } & \text { ball valve, } \\ \text { P } & \text { gear flow meter, } \\ \text { RP1 -6 } & \text { two-way flow controller, }\end{array}$

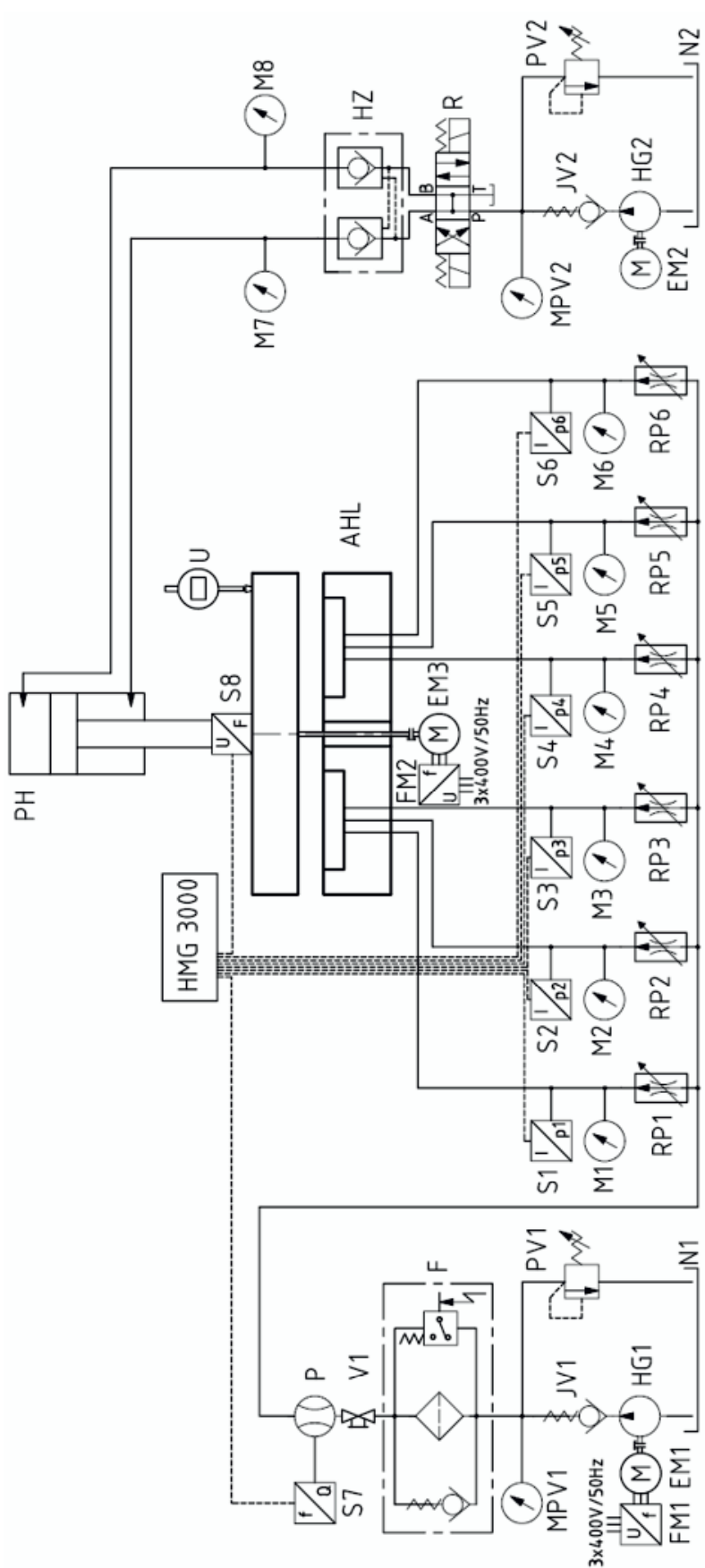

Figure 3. The scheme of hydraulic circuit of the experimental equipment.

$\begin{array}{ll}\text { M1 }-8 & \text { manometer, } \\ \text { AHL } & \begin{array}{l}\text { hydrostatic thrust bearing, } \\ \text { digital indicator, } \\ \text { U }\end{array} \\ \text { PH } & \text { hydraulic motor, } \\ \text { valve } 3 / 4, \\ \text { HZ } & \text { pilot operated check valve, } \\ \text { pressure sensor, } \\ \text { S7 } & \text { flow sensor, } \\ \text { S8 } & \text { force sensor, } \\ \text { ND } & \text { bearing plate, } \\ \text { NK } & \text { bearing construction, } \\ \text { H } & \text { shaft, } \\ \text { P } & \text { bearing sleeve, } \\ \text { RKL } & \text { radial plain bearing, } \\ \text { AKL } & \text { ball thrust bearing, }\end{array}$


S

AS

HMG 3000 nut,

arresting nut,

equipment for data measurement and collection for hydraulic and pneumatic systems.

\section{Bearing construction and arresting device of the hydrostatic thrust bearing}

On the bearing construction (NK) of the experimental equipment the bearing desk (ND) is positioned, to which the bottom plate of the hydrostatic thrust bearing (AHL) is firmly fixed, see figure 4 . The whole construction of the equipment is designed to withstand the maximum static load of $10000 \mathrm{~kg}$.

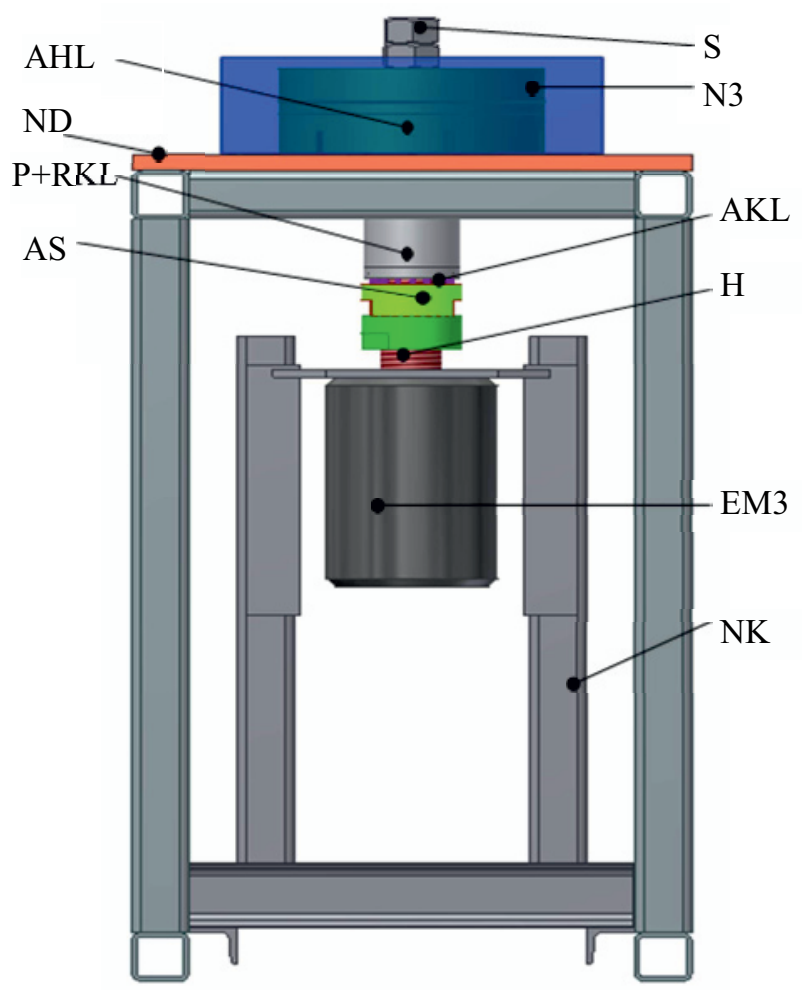

Figure 4. Scheme of the bearing construction and arresting device.

During the movement of the hydrostatic thrust bearing a mineral oil is drained into the tank (N3), which is mounted on the bearing desk (ND). The fluid is transported due to the gravity through two draining pipes to the tank (N1).

Torsional moment of the electric motor (EM3) is transmitted through the shaft $(\mathrm{H})$ on the movable plate of the bearing, which is screwed to it and secured by two nuts (S) against release during the rotary motion. Under the bearing desk there is also located the arresting device, which is used to set the maximum lift of the movable plate of the hydrostatic thrust bearing. The shaft is connected to the electric motor by the gear coupling, which allows small vertical movement of the shaft. By the connection of the electric motor with the shaft and upper plate of the bearing rotational movement is provided. Parallelism and concentricity of sliding surfaces of the hydrostatic thrust bearing are ensured with two radial bearings. Bearing sleeve $(\mathrm{P})$ is welded to the bearing desk and is fitted with the bronze radial sliding bearing (RKL) and with bearing in electric motor form a pair of sliding bearings.

The adjusting of the vertical motion is secured with the arresting nuts (AS). These arresting nuts are positioned between the bearing sleeve and electric motor on the shaft. The gap between the upper arresting nut and bearing sleeve $(\mathrm{P})$ correspond to the maximum allowable clearance of the fluid layer in the hydrostatic thrust bearing. The arresting nuts have M64 thread with lead 1.5 $\mathrm{mm}$. The upper arresting nut is connected with ball thrust bearing (AKL). By applying pressure energy to the hydrostatic thrust bearing the upper movable plate is lifted. In case of maximum lift, the arresting nut with ball thrust bearing rests to the bearing sleeve. During the rotary motion of the shaft it could lead to unscrewing of the top of arresting nut, and therefore the lower arresting nut is used to secure its position.

\section{Specification of mineral oil for experimental equipment}

One of the most important factors that affect the proper function of the hydrostatic thrust bearing is the choice of lubricant. Mineral oil is used to transfer the pressure energy in the hydraulic circuit and loading forces acting on the bearing.

For transfer of pressure energy from the hydraulic aggregate to the hydrostatic thrust bearing paraffinic mineral oil for slide ways Mobil Vactra No. 3 is used. Mineral oil is used for slide ways with high pressure and for equipment, where the high precision of moving parts is required, e.g. for machine tools. The additives are added to the basic oil to improve its properties [5].

The viscosity curve of mineral oil Mobil Vactra No. 3 (figure 5) was measured with rotational viscometer Brookfield Model DV-II+ Pro. Parameters of mineral oil are summarized in table 1 . These parameters were obtained from measurements and technical list for the oil $[3,6,7]$.

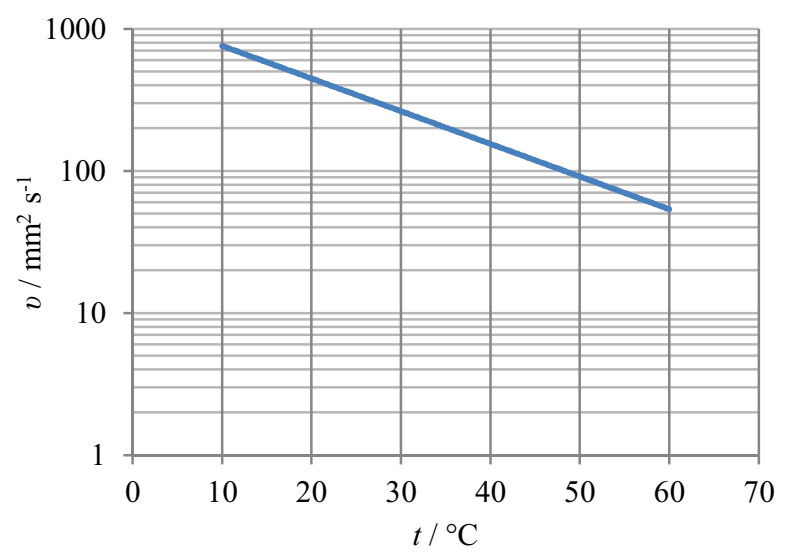

Figure 5. Dependence of kinematic viscosity of Mobil Vactra No. 3 on temperature. 
Table 1. Parameters of mineral oil.

\begin{tabular}{|l|c|}
\hline \multicolumn{2}{|c|}{ Mineral oil Mobil Vactra No. 3} \\
\hline Density $\rho\left(\mathrm{kg} \mathrm{m}^{-3}\right)$ at $20{ }^{\circ} \mathrm{C}$ & 872 \\
\hline Kinematic viscosity $v\left(\mathrm{~mm}^{2} \mathrm{~s}^{-1}\right)$ at: \\
\hline $10^{\circ} \mathrm{C}$ & 752 \\
\hline $20{ }^{\circ} \mathrm{C}$ & 471 \\
\hline $30{ }^{\circ} \mathrm{C}$ & 244 \\
\hline $40{ }^{\circ} \mathrm{C}$ & 154 \\
\hline $50{ }^{\circ} \mathrm{C}$ & 95 \\
\hline $60{ }^{\circ} \mathrm{C}$ & 53 \\
\hline Viscous index & VI 96 \\
\hline Pour point $\left({ }^{\circ} \mathrm{C}\right)$ & -6 \\
\hline Flash point $\left({ }^{\circ} \mathrm{C}\right)$ & 248 \\
\hline Specific heat capacity $c_{p}\left(\mathrm{~J} \mathrm{~kg}^{-1} \mathrm{~K}^{-1}\right)$ & 1866 \\
\hline
\end{tabular}

\section{Measurement of physical properties of the experimental equipment}

Using the experimental equipment the following physical quantities can be measured:

* static load of the hydrostatic thrust bearing $F$ and pressure in the hydraulic motor $p_{h m}$, which generates the force,

* total volumetric flow-rate of the pump $Q_{v}$,

* the height of the fluid layer of the hydrostatic thrust bearing $h$,

* rotational speed of the hydrostatic thrust bearing $n$,

* pressure at the inlet to the hydrostatic thrust bearing $p_{1}-p_{6}$.

During the measurement of physical quantities, constant volumetric flow-rate will be maintained by twoway flow controller. The parameters will be measured at different values of the axial load, and also for various values of volumetric flow rate. Pump enables to change the flow-rate in range from $01 \mathrm{~min}^{-1}$ to $7.21 \mathrm{~min}^{-1}$. Size of the current load of the hydrostatic thrust bearing will be measured using a force sensor. The load will be generated by hydraulic motor.

Figure 6 shows the dependence of force $F$ on pressure in hydraulic motor $p_{h m}$. Loading capacity $m$ of the hydrostatic thrust bearing can be clearly and easily identified by adding third auxiliary axes.

\section{Conclusions}

Experimental equipment for measuring the physical properties of the hydrostatic thrust bearing was designed and built within the project SP2012/55. The individual parts of the experimental stand were described in details which are necessary for the proper function of the equipment. Hydraulic circuit was designed which serves as a source of pressure energy. Also the method of the hydrostatic thrust bearing control was described as well as the arresting device for regulation of the fluid layer clearance.

The important element of the hydrostatic thrust bearing is a mineral oil which has several important functions - it transmits the pressure energy, provides lubrication of hydraulic components, dissipates heat, etc.

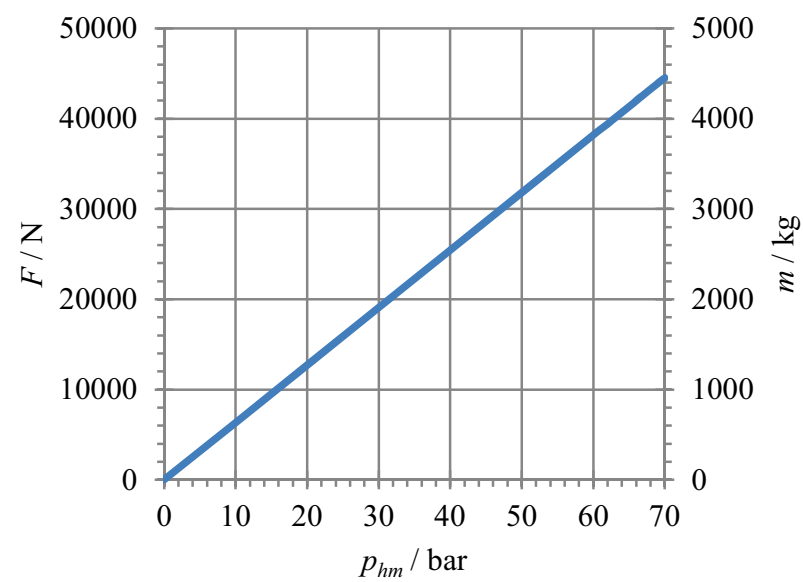

Figure 6. The dependence of force on pressure.

\section{References}

1. M. Kozdera, S. Drábková, Exp. Fluid Mech. (EPJ Web of Conf.), 45 (2013)

2. O. Janeček, Strojírenství 38, 6 (1988)

3. M. Kozdera, S. Drábková, Riadenie tek. syst., 13 (2013)

4. H. C. Rippel, Cast Bronze Hydrostatic Bearing Design Manual (1964)

5. R. Bassani, B. Piccigallo, Hydrostatic Lubrication (1992)

6. M. Neal, Tribology Handbook (1973)

7. A. Cameron, Basic lubrication theory (1971)

The results presented in this paper were achieved within the specific research project SP2012/55 "Modelováni dynamiky tekutinových mechanismü" solved at Faculty of Mechanical Engineering, VŠB - Technical University of Ostrava in 2012. 